\title{
Adverse Outcomes Following Free Tissue Transfer: A 3-year Experience From a Major Referral Centre
}

\section{Silas Nann ( $\square$ snann134@gmail.com )}

Flinders Medical Centre

Jia Miin Yip

Flinders Medical Centre

Tyler Glanville

Flinders Medical Centre

Nicholas Marshall

Flinders Medical Centre

\section{Research Article}

Keywords: free flaps, free tissue transfer flaps, microsurgical free flaps, breast reconstruction, complications

Posted Date: December 29th, 2021

DOI: https://doi.org/10.21203/rs.3.rs-1143058/v1

License: (a) This work is licensed under a Creative Commons Attribution 4.0 International License. Read Full License 


\section{Abstract}

\section{Background}

Free tissue transfer encompasses a variety of techniques by which tissue is moved to another region of the body, with anastomosis of the divided artery and vein. Currently, success rates are reported at 91-99\% [1], however, little is known regarding predictors for adverse outcomes. We aim at identifying predictors for negative outcomes following free flap surgery; and predict that elderly patients and patients with head and neck free flaps will have inferior outcomes due to comorbidity.

Methods

This is a retrospective case series. All free flap surgeries between 02/2018 to 02/2021 were identified using the electronic operation record system at Flinders Medical Centre. Chi squared hypothesis testing assessed patient factors and implications on outcome.

\section{Results}

67 patients of varying demographics were included in this study. The odds of wound infection was much higher in patients aged older than 65 (OR: $4.1(95 \% \mathrm{Cl} 1.24-13.6, \mathrm{z}$-score: $2.31, \mathrm{p}=0.017))$. The odds of unplanned reoperation was also higher in this population (OR: $13.7(95 \% \mathrm{Cl} 1.42-132.9, \mathrm{p}=0.0053)$ ). Free flap location was significant in determining whether patients would require a subsequent blood transfusion $(p=0.0071)$. Head and neck patients did not experience a higher rate of adverse events.

Conclusion

Patients aged 65 and older are more likely to require treatment for infection and more often require reoperation because of flap related issues. Patients with limb free flaps are more likely to require transfusions. Head and neck patients did not have higher complication rates.

\section{Introduction}

The first recorded successful free flap reconstruction was reported in 1972 [2]. Since this time, numerous techniques have evolved in relation to the transfer of free tissue from one region of the body to another. Microvascular surgery is utilised to anastomose donor blood vessels to regional blood supply at the recipient site. Free tissue transfer is the final rung in the reconstructive ladder and should only be utilised when other all reconstructive techniques are deemed inferior for the clinical problem at hand. For this reason, thought must be given to potential perioperative complications that can adversely affect patient outcomes.

Since 1972, surgical techniques pertaining to free tissue transfer have continued to improve. Currently, success rates are reported between 91 to $99 \%$. [1] Regardless, this patient population is at great risk for postoperative complications. Formeister reported that $45.6 \%$ of patients undergoing free tissue transfer 
experienced an adverse event during admission. [3] Tam found that $18.8 \%$ of patients required an unplanned return to theatre. [4] For free fibular bone flaps, it has been reported that 48 major recipient site complications occurred in 41 reconstructions. [5] Because free flap patients are at significant risk of adverse outcomes, it is important to identify predictors for complications and to identify groups most at risk.

Previous publications have found patient risk factors for complications, however, to date, there is no clear consensus regarding free tissue transfers. Low skeletal muscle mass [6], increased alcohol consumption [4], age [3, 7, 8], higher ASA [8], flap type, and site of reconstruction [3] have all been shown to increase the incidence of medical and surgical complications. Obesity has not demonstrated an increased number of adverse events. In fact, higher body weight has been protective in some cases [9]. Many authors have been unable to find an association between advanced age and harmful outcomes [10-14]. Further research is needed to delineate associations between free flap reconstructive surgery and any subsequent complications.

The objective of this study is to identify predictors for negative outcomes following free flap surgery. We aim to compare free flaps by body region, age, and gender. We predict that elderly patients and patients with head and neck free flaps will have inferior outcomes because these populations are more likely affected by co-morbidity.

\section{Methods}

This is a single centre retrospective case series. All cases of free tissue transfer occurring between 28th February 2018 and 17th Feburary 2021 were collated using the theatre electronic medical records system at a large tertiary centre in Adelaide, South Australia. 67 cases were identified. Case files and discharge summaries were then retrospectively analysed to identify complications that occurred as a result of the operation. Chi squared hypothesis testing was used to identify factors that contribute to negative outcomes for patients. Patients outcomes were deliniated by body region (head and neck, breast, limbs), age, and gender.

\section{Ethics approval}

was sought from the Southern Adelaide Clinical Human Research Ethics Committee and the need for informed consent was waived due to the retrospective nature of the study. Research was performed in accordance with relevant guidelines and regulations. Patient data was stored and managed in accordance with the Australian Code for the responsible Conduct of research. Informed consent is not required for this type of study. The authors have no conflict of interest to disclose. The authors did not receive support from any organisation for the submitted work. The authors received no financial support for the research, authorship, and/or publication of this article.

\section{Results}




\section{Patient Demographics}

Table 1 provides an overview of the patient demographic data included in this study. A total of 67 patients underwent free tissue transfer. Patients ranged from 18 to 86 years of age, with an average of 57. Almost half of the patients were aged between 46 to 64 years. There were 37 males and 30 females, with a ratio of 1.23 to $1.46 .3 \%$ of patients in this cohort experienced at least one complication. This was more likely to occur in the elderly with $61.1 \%$ of patients over the age of 65 being affected. Only $40.8 \%$ of patients younger than 65 experienced a complication. This trend also holds true for major complications. The elderly were more than twice as likely to experience a major problem (defined as a Clavien-Dindo Classification grade of Illa or higher). [15] $44.4 \%$ of cases required substantial unplanned post-operative intervention, compared to $20.4 \%$ of the younger cohort. Breast reconstruction patients were less likely to experience any complication with $36.8 \%$ of cases affected, compared to $48.4 \%$ of head and neck patients and $52.9 \%$ of limb patients. No differences were found in terms of incidence of major complications between body regions. 
Table 1

Patient demographic

\begin{tabular}{|c|c|}
\hline & No. of participants $(n=67)$ \\
\hline Age & 49 \\
\hline$<65$ years & 18 \\
\hline \multirow[t]{2}{*}{$\geq 65$ years } & Mean age: 57 \\
\hline & Age range: 18 to 86 \\
\hline Gender & 37 \\
\hline Male & 30 \\
\hline Female & M:F Ratio: 1.23:1 \\
\hline Flap Location & 31 \\
\hline Head and neck & 19 \\
\hline Breast & 17 \\
\hline \multicolumn{2}{|l|}{ Limb } \\
\hline Flap Type & 21 \\
\hline Radial/ Ulnar & 19 \\
\hline TRAM & 7 \\
\hline Latissimus dorsi & 7 \\
\hline Anterolateral thigh & 7 \\
\hline Gracilis & 2 \\
\hline Tempero-parietal & 1 \\
\hline Fibular & 1 \\
\hline Lateral arm & 1 \\
\hline Other & 1 \\
\hline Rectus Abdominis muscle only & \\
\hline
\end{tabular}




\begin{tabular}{|c|c|}
\hline & No. of participants $(n=67)$ \\
\hline Total complications number & $31 / 67(46.3 \%)$ \\
\hline$\geq 65$ & 11/18 (61.1\%) \\
\hline$<65$ & $20 / 49(40.8 \%)$ \\
\hline Head and neck & 15/31 (48.4\%) \\
\hline Breast & $7 / 19(36.8 \%)$ \\
\hline Limb & $9 / 17(52.9 \%)$ \\
\hline Major complications number & $18 / 67(26.9 \%)$ \\
\hline$\geq 65$ & $8 / 18$ (44.4\%) \\
\hline$<65$ & $10 / 49(20.4 \%)$ \\
\hline Head and neck & $8 / 31(25.8 \%)$ \\
\hline Breast & $5 / 19(26.3 \%)$ \\
\hline Limb & $5 / 17(29.4 \%)$ \\
\hline
\end{tabular}

\section{Complications by age}

Table 2 categorises adverse events data by age. The accompanying figure 1 provides a visual analysis of the same. A total of 49 patients were younger than 65 and 18 patients were older than 65 . It was found that older patients were more likely to require an unplanned return to theatre and were much more likely to develop a post-operative infection of the reconstructed site. The odds ratio for a patient over the age of 65 to require a return to theatre was 4.1. This was statistically significant with a p-value of 0.017 . The odds ratio for developing a free flap infection was 13.71. This was statistically significant with a p-value of 0.0053. No significant difference was found in terms of death, unplanned ICU, anaemia requiring transfusion, and rates of total flap failure. 
Table 2

Complications by age

\begin{tabular}{|c|c|c|c|c|}
\hline Complication & $\begin{array}{l}<65 \text { years \% } \\
(n=49)\end{array}$ & $\begin{array}{l}\geq 65 \text { years } \% \\
(n=18)\end{array}$ & $\begin{array}{l}\text { Odds Ratio (95\% } \\
\text { Cl) }\end{array}$ & $\begin{array}{l}\text { Chi^ } 2 \mathrm{p}- \\
\text { value }\end{array}$ \\
\hline Death & $2.04(n=1)$ & 0 & $\mathrm{~N} / \mathrm{A}$ & 0.54 \\
\hline Total flap failure & $4.08(n=2)$ & $11.11(n=2)$ & $\begin{array}{l}2.94(0.38- \\
22.60)\end{array}$ & 0.28 \\
\hline Unplanned return to theatre & $16.33(n=8)$ & $44.44(n=8)$ & $\begin{array}{l}4.1(1.24- \\
13.60)\end{array}$ & $0.017 * \star$ \\
\hline $\begin{array}{l}\text { Unplanned intensive care } \\
\text { admission }\end{array}$ & 0 & $5.56(n=1)$ & $\mathrm{N} / \mathrm{A}$ & 0.096 \\
\hline Reconstructed site infection & $2.04(n=1)$ & $22.22(n=4)$ & $\begin{array}{l}13.71(1.42- \\
132.85)\end{array}$ & $0.0053^{* * *}$ \\
\hline $\begin{array}{l}\text { Anaemia requiring } \\
\text { transfusion }\end{array}$ & $12.25(n=6)$ & $16.67(n=3)$ & $\begin{array}{l}1.23(0.32- \\
6.46)\end{array}$ & 0.64 \\
\hline Other/ medical & $22.45(n=11)$ & $16.67(n=3)$ & $\begin{array}{l}0.69(0.17- \\
2.83)\end{array}$ & 0.61 \\
\hline
\end{tabular}

\section{*** significant at the $99 \%$ level}

\section{** significant at the $95 \%$ level}

\section{Complications by body region}

Table 3 groups complications data by the site of surgery. This information is also presented visually in figure 2. A total of 31 patients underwent head and neck free flaps, 19 patients underwent breast free flaps, and 17 patients underwent limb free flaps. It was found that free flap location was significant in determining whether patients would require a subsequent blood transfusion, with a p-value of 0.0071 . There was no statistically significant difference in terms of complication rates between body regions for death, unplanned ICU admission, unplanned return to theatre, flap failure, and reconstructed site infection. 
Table 3

Complications by body region

\begin{tabular}{|c|c|c|c|c|}
\hline Complication & $\begin{array}{l}\text { Head and Neck \% } \\
(n=31)\end{array}$ & $\begin{array}{l}\text { Breast \% } \\
(n=19)\end{array}$ & $\begin{array}{l}\operatorname{Limb} \% \\
(n=17)\end{array}$ & $\begin{array}{l}\text { Adjusted Chi^2 (p- } \\
\text { value) }\end{array}$ \\
\hline Average age & 64 & 52 & 50 & \\
\hline Death & 0 & 0 & $5.88(n=1)$ & $2.99(0.22)$ \\
\hline Total flap failure & $6.45(n=2)$ & $10.53(n=2)$ & 0 & $1.85(0.40)$ \\
\hline Unplanned return to theatre & $25.81(n=8)$ & $21.05(n=4)$ & $\begin{array}{l}23.52 \\
(n=4)\end{array}$ & $0.15(0.93)$ \\
\hline $\begin{array}{l}\text { Unplanned intensive care } \\
\text { admission }\end{array}$ & 0 & 0 & $5.88(n=1)$ & $2.99(0.22)$ \\
\hline Reconstructed site infection & $9.68(n=3)$ & $5.26(n=1)$ & $5.88(n=1)$ & $0.42(0.81)$ \\
\hline $\begin{array}{l}\text { Anaemia requiring } \\
\text { transfusion }\end{array}$ & $3.21(n=1)$ & $10.53(n=2)$ & $\begin{array}{l}35.29 \\
(n=6)\end{array}$ & $9.90\left(0.0071^{\star \star \star}\right)$ \\
\hline Other/ medical & $16.13(n=5)$ & $10.53(n=2)$ & 0 & $3.05(0.22)$ \\
\hline
\end{tabular}

There were no statistically significant differences found between males and females in terms of postoperative free flap complication rates.

\section{Discussion}

This study demonstrates that free flaps are a generally safe and successful procedure. The overall mortality was $1.5 \%$ and overall flap success was $92.5 \%$. These numbers are similar to other studies [1, 16]. There was no difference in incidence of total flap failure or death in patients older than 65 years. It can therefore be concluded that age does not predispose to failure of the procedure. In keeping with our findings, Ferrari et al concludes that as long as patients are carefully selected pre-operatively in terms of comorbidities, age should not be a disqualifying factor for reconstruction with free flaps. [16]

The total percentage of cases affected by a complication according to the Clavien-Dindo classification was $46.3 \%$. This is in line with other publications. [3] The likelihood of a major complication was $26.9 \%$. The elderly were more likely to experience any complication and much more likely to experience a grade Illa complication or higher, compared to younger patients. Breast patients were less likely to experience any complication, compared to other body regions. No difference was found in terms of major complications between body regions. It can therefore be concluded that age is a suitable predictor of 
worse post-operative outcomes, while breast reconstruction patients are more likely to have a favourable recovery period.

Overall, it was found that the elderly were much more likely to require reoperation and develop postoperative reconstructed site infection. $45 \%$ of free flaps over the age of 65 required an unplanned return to theatre. The most common reasons for this were wound breakdown, flap congestion, and haematoma formation. $22 \%$ of elderly patients also developed infection of the reconstructed site and required treatment with antibiotics. Only $2 \%$ of younger patients also experienced this complication. Currently, the literature suggests that elderly patients are 3-4 times more likely to develop chronic wounds because of difficulty with wound healing. This is thought to be secondary to prolongation of the inflammatory phase of healing, macrophage dysfunction, and malnutrition. [17] Regardless, these findings highlight the need for careful monitoring of elderly patients post operatively, in terms of flap health, but also in terms of overall physiology. There should be a low threshold to initiate antibiotic prophylaxis when free flap infection is suspected in patients aged 65 or older.

Head and neck free flaps are most commonly performed following resection of cancers in this body region. In general, these patients are well known to be more medically co-morbid than other patient populations. In this patient population, the average age for patients with head and neck free flaps was 64 . This was 12 years older, on average, than breast patients and 14 years older than limb patients. Since elderly patients are more likely to be co-morbid, this patient population would have therefore been considered a higher pre-operative risk. Our findings suggest that despite this, the rate of all complications is not significantly increased. Head and neck free flaps are not more likely to result in complications. Other authors report similar results, although it is interesting to note that Las et al found significantly reduced rates of post-operative infection and total flap failure in patients undergoing breast reconstruction. [18]

In this study, patients undergoing limb operations were found to be significantly more likely to require a blood transfusion peri-operatively. The most common indication for reconstruction involving limbs was trauma. Many of these free flaps were performed following orthopaedic intervention or to reconstruct significant soft tissue loss following trauma. Blood loss is therefore more likely related to the mechanism of injury and orthopaedic interventions, rather than directly to the free flap itself. Regardless, these findings suggest that patients undergoing limb free flap reconstruction, especially in the setting of trauma, will require more careful monitoring of haemoglobin levels than other patient populations.

As predicted, there was no difference in complication incidence between male and female patients.

The main limitation of this study is that this is a single centre retrospective analysis. Generalisability is therefore limited. The sample size is also small.

\section{Conclusion}


This study found that elderly patients were more likely to experience any complication and much more likely to experience a major complication. In particular, patients aged 65 and older were more likely to require an unplanned return to theatre (OR 4.1) and were much more likely to develop a post-operative reconstructed site infection (OR 13.7). This highlights the need for careful post-operative monitoring of elderly patients. Patients undergoing limb operations were more likely to require a blood transfusion, although this is likely related to trauma as the most common indication for surgery. No difference was found in terms of complication rates between head and neck patients and other patient groups.

\section{Declarations}

\section{DISCLOSURES}

Ethics approval was sought from the Southern Adelaide Clinical Human Research Ethics Committee and the need for informed consent was waived due to the retrospective nature of the study. Informed consent is not required for this type of study. The authors have no conflict of interest to disclose. The authors did not receive support from any organisation for the submitted work. The authors received no financial support for the research, authorship, and/or publication of this article.

\section{References}

1. Chen K-H, Kuo SCH, Chien P-C, et al (2021) Comparison of the surgical outcomes of free flap reconstruction for primary and recurrent head and neck cancers: a case-controlled propensity scorematched study of 1,791 free flap reconstructions. Sci Rep 11:2350. https://doi.org/10.1038/s41598-02182034-5

2. Lese I, Biedermann R, Constantinescu M, et al (2021) Predicting risk factors that lead to free flap failure and vascular compromise: A single unit experience with 565 free tissue transfers. J Plast Reconstr Aesthet Surg 74:512-522. https://doi.org/10.1016/j.bjps.2020.08.126

3. Formeister EJ, Baum R, Knott PD, et al (2020) Machine Learning for Predicting Complications in Head and Neck Microvascular Free Tissue Transfer. The Laryngoscope 130:E843-E849. https://doi.org/10.1002/lary.28508

4. Tam S, Weber RS, Liu J, et al (2020) Evaluating Unplanned Returns to the Operating Room in Head and Neck Free Flap Patients. Ann Surg Oncol 27:440-448. https://doi.org/10.1245/s10434-01907675-3

5. van Gemert JTM, Abbink JH, van Es RJJ, et al (2018) Early and late complications in the reconstructed mandible with free fibula flaps. J Surg Oncol 117:773-780.

https://doi.org/10.1002/jso.24976

6. Ansari E, Chargi N, van Gemert JTM, et al (2020) Low skeletal muscle mass is a strong predictive factor for surgical complications and a prognostic factor in oral cancer patients undergoing 
mandibular reconstruction with a free fibula flap. Oral Oncol 101:104530. https://doi.org/10.1016/j.oraloncology.2019.104530

7. Farquhar DR, Masood MM, Pappa AK, et al (2018) Predictors of Adverse Outcomes in Free Flap Reconstruction: A Single-Institution Experience. Otolaryngol Neck Surg 159:973-980. https://doi.org/10.1177/0194599818787801

8. Weitgasser L, Amr A, Hladik M, et al (2019) The Impact of Age on Perioperative Complications after Extremity Reconstruction with the Free Gracilis Flap: A Retrospective Cohort Study Involving 153 Patients. J Reconstr Microsurg 35:395-410

9. Crippen MM, Brady JS, Mozeika AM, et al (2018) Impact of Body Mass Index on Operative Outcomes in Head and Neck Free Flap Surgery. Otolaryngol Neck Surg 159:817-823. https://doi.org/10.1177/0194599818777240

10. Spindler N, Pieroh P, Spiegl U, et al (2021) Free Flap Reconstruction of the Extremities in Patients Who are $\geq 65$ Years Old: A Single-Center Retrospective 1-to-1 Matched Analysis. Clin Interv Aging 16:497503. https://doi.org/10.2147/CIA.S300558

11. Spoerl S, Schoedel S, Spanier G, et al (2020) A decade of reconstructive surgery: outcome and perspectives of free tissue transfer in the head and neck. Experience of a single center institution. Oral Maxillofac Surg 24:173-179. https://doi.org/10.1007/s10006-020-00838-7

12. Otsuki N, Furukawa T, Avinçsal MO, et al (2020) Results of free flap reconstruction for patients aged 80 years or older with head and neck cancer. Auris Nasus Larynx 47:123-127.

https://doi.org/10.1016/j.anl.2019.04.005

13. Parsemain A, Philouze P, Pradat $P$, et al (2019) Free flap head and neck reconstruction: Feasibility in older patients. J Geriatr Oncol 10:577-583. https://doi.org/10.1016/j.jgo.2018.11.002

14. Torabi R, Stalder MW, Tessler O, et al (2018) Assessing Age as a Risk Factor for Complications in Autologous Breast Reconstruction. Plast Reconstr Surg 142:

15. Dindo D, Demartines N, Clavien P-A (2004) Classification of surgical complications: a new proposal with evaluation in a cohort of 6336 patients and results of a survey. Ann Surg 240:205-213. https://doi.org/10.1097/01.sla.0000133083.54934.ae

16. Ferrari S, Copelli C, Bianchi B, et al (2013) Free flaps in elderly patients: Outcomes and complications in head and neck reconstruction after oncological resection. J Cranio-Maxillofac Surg 41:167-171. https://doi.org/10.1016/j.jcms.2012.07.005

17. Gould L, Abadir P, Brem H, et al (2015) Chronic Wound Repair and Healing in Older Adults: Current Status and Future Research. J Am Geriatr Soc 63:427-438. https://doi.org/10.1111/jgs.13332 
18. Las DE, de Jong T, Zuidam JM, et al (2016) Identification of independent risk factors for flap failure: A retrospective analysis of 1530 free flaps for breast, head and neck and extremity reconstruction. J Plast Reconstr Aesthet Surg 69:894-906. https://doi.org/10.1016/j.bjps.2016.02.001

\section{Figures}

\section{Complications by age}

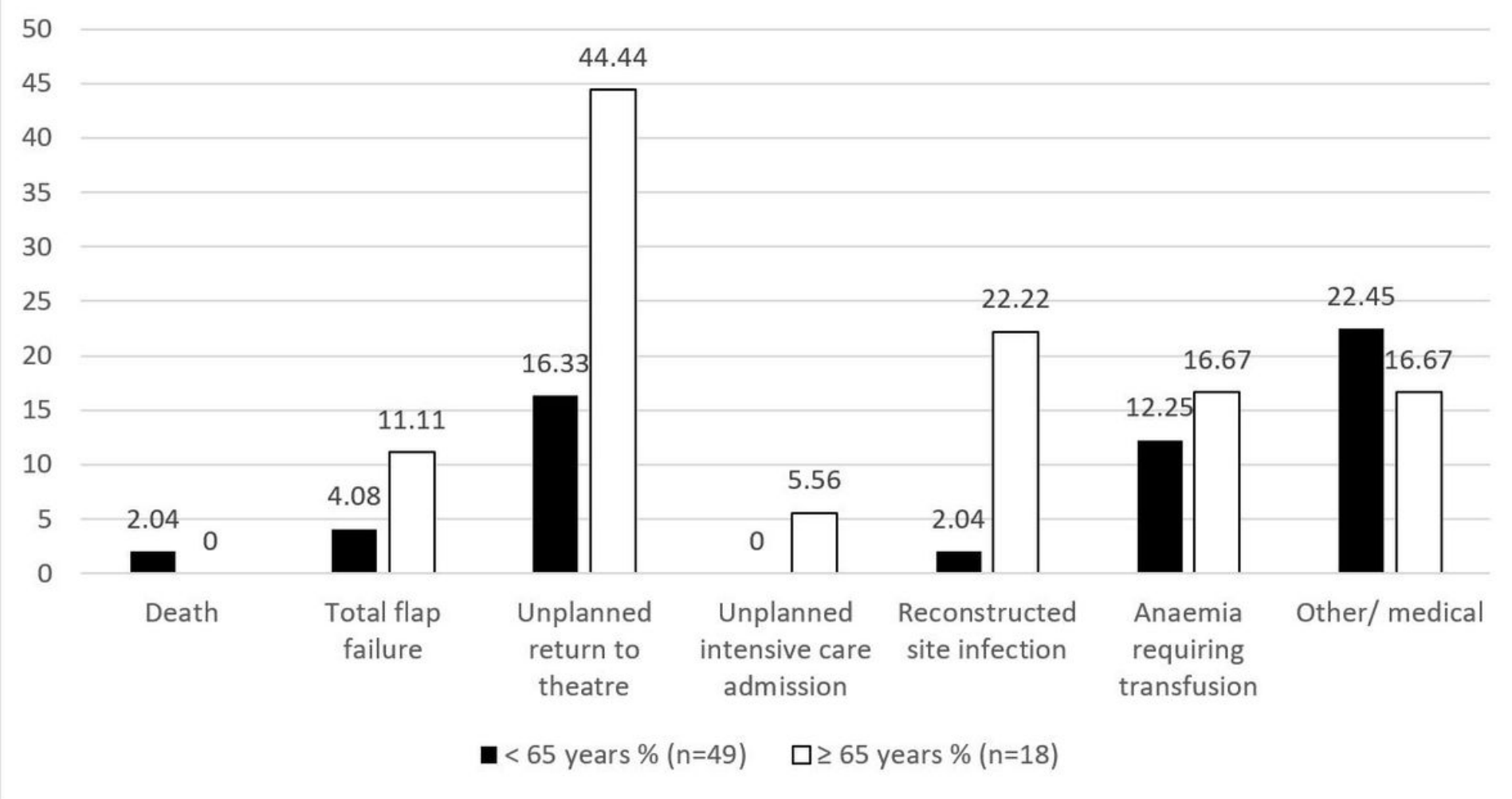

\section{Figure 1}

Complications by age 


\section{Complications by body region}

40

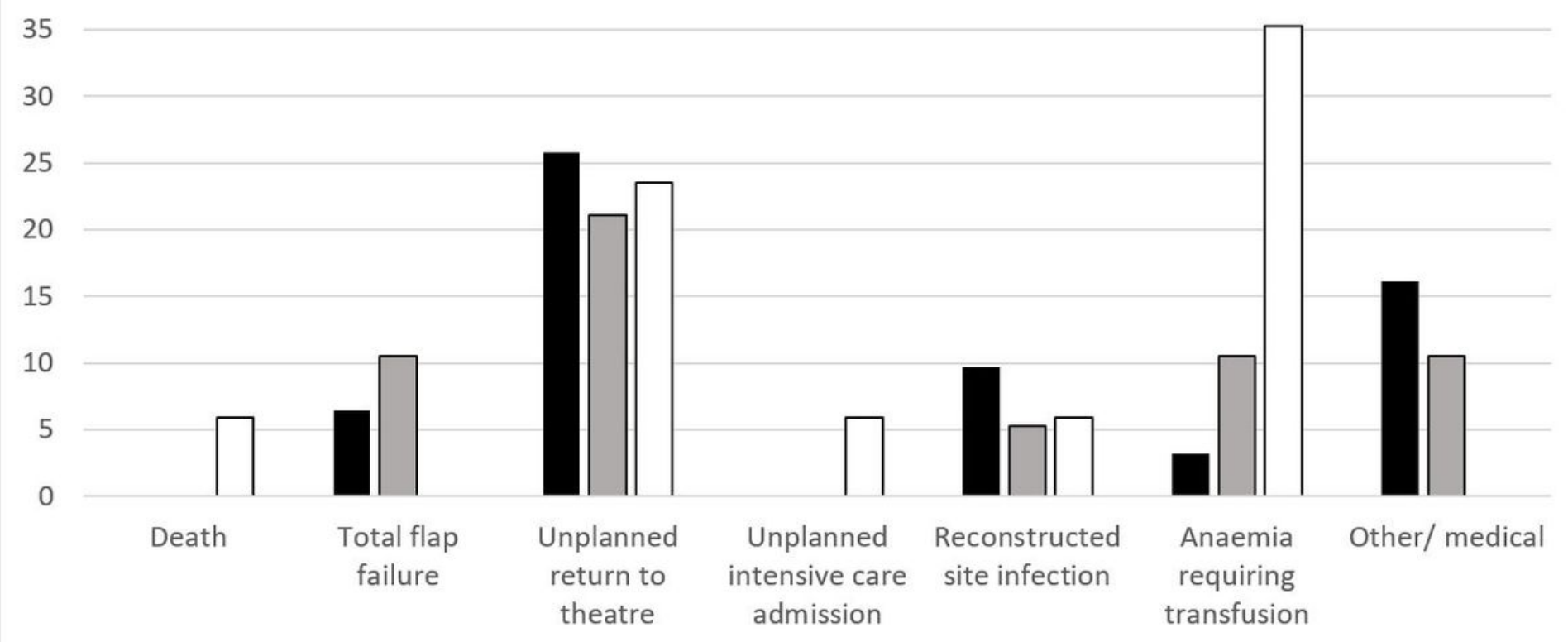

- Head and Neck \% (n=31) $\quad \square$ Breast \% $(n=19) \quad \square$ Limb \% (n=17)

Figure 2

Complications by body region 